\title{
Pesquisa e Desenvolvimento na Cadeia Produtiva de Frangos de Corte no Brasil ${ }^{1,2}$
}

\author{
Nádia Solange Schmidt ${ }^{3}$ e Christian Luiz da Silva ${ }^{4}$
}

Resumo: Nos últimos anos, a produção de carne de frango brasileira cresceu $112 \%$. Esse desempenho posicionou o Brasil como o maior exportador e o terceiro maior produtor mundial. A cadeia produtiva de frangos de corte é representada por milhares de produtores, diversas empresas beneficiadoras e exportadoras. Sua organização, capacidade gerencial, inovações tecnológicas introduzidas e o uso de um sistema eficiente de Pesquisa e Desenvolvimento (P\&D) ${ }^{5}$ foram as razões desse sucesso. $\mathrm{O}$ presente artigo analisou o processo de P\&D dessa cadeia, nas etapas de produção e industrialização, por meio de uma pesquisa qualitativa, com uso de questionários semiestruturados. Os resultados obtidos permitem concluir que a maior parte das empresas pesquisadas têm estrutura própria de P\&D e desenvolvem pesquisa mais fortemente direcionada para o desenvolvimento de produtos ou processos, algumas buscando inovações tecnológicas, outras apenas testando produtos já desenvolvidos. Um fato positivo é que as instituições públicas, como universidades e IPPs (Institutos Públicos de Pesquisa), são parceiros importantes nesse processo, o que demonstra confiança nessas instituições, além da preocupação em maximizar os recursos físicos, humanos e financeiros.

Palavras-chaves: cadeia produtiva de frangos, pesquisa e desenvolvimento, Institutos Públicos de Pesquisa.

Abstract: Over the last years, the production of Brazilian broiler increased by 112\%, pushing up exports sharply. This excellent performance has settled Brazil as the largest exporter and third largest producer of broiler. Thousands of producers and hundreds of processing and exporting companies represent this sector. Its organization, use of technology and management skills have been an example of success for other meat chains. This success resulted from technological innovations, as well as the

1. Data de submissão: 10 de março de 2016. Data de aceite: 26 de novembro de 2017.

2. Os autores agradecem a Fundação Araucária de Apoio ao Desenvolvimento Científico e Tecnológico do Paraná pelo apoio financeiro ao projeto: Prospecção de tecnologias para a cadeia produtiva de aves de corte - Convênio 336/2014.

3. Empresa Brasileira de Pesquisa Agropecuária (Embrapa), Concórdia, Santa Catarina, Brasil. E-mail: nadia.schmidt@embrapa.br

4. Universidade Tecnológica Federal do Paraná (UTFPR), Curitiba, Paraná, Brasil. E-mail: christiansilva@utfpr.edu.br

5. O termo P\&D utilizado neste artigo refere-se a atividades de pesquisa e desenvolvimento, caracterizadas pela existência de estrutura de pesquisa como laboratórios, campos experimentais e equipe técnica (pesquisadores). 
use of an efficient system of Research and Development (RED). This article aims to analyze the RED process in the production chain of Brazilian broiler, especially the stages of production and industrialization. A search had been carried out with the use of semi-structured questionnaires with professionals in the production and industrialization areas. The results showed that most of the surveyed companies has its own structure of RED and develop research more strongly directed to the development of products or processes, some more intensively, looking for technological innovations, and others just test products already developed. A positive fact is that public institutions, such as universities and PRIs (Public Research Institutes), are important partners in this process, which demonstrates confidence in these institutions, as well as a concern to maximize physical, human and financial resources.

Key-words: broiler productive chain, research and development, Public Research Institutes.

Classificação JEL: 032.

DOI: http://dx.doi.org/10.1590/1234-56781806-94790560307

\section{Introdução}

A cadeia produtiva de frangos de corte no Brasil tem vantagens competitivas devido ao rápido ciclo produtivo, ao fato de ter a possibilidade de uma estrutura organizacional verticalizada e de ser uma proteína de baixo custo, o que atrai consumidores de diferentes classes sociais (RECK e SCHULTZ, 2016). Ela é caracterizada, como mostram Gordin e Oliveira (2003), Reck e Schultz (2016) e Espíndola (2012), pelo uso de sistemas modernos de planejamento, organização, coordenação, técnicas gerenciais e, principalmente, pela incorporação de novas tecnologias que resultam em um constante crescimento da produção. Espíndola (2012) destaca que a incorporação das novas tecnologias possibilitou a melhoria nos sistemas de produção e controle, a redução dos custos de energia e matéria-prima, a diversificação da matriz energética e do mix de produtos industrializados oferecidos. Os grandes avanços da pesquisa no desenvolvimento de novas tecnologias no setor da avicultura converteram o Brasil em um dos maiores produtores e exportadores de carne de frango mundiais.

Segundo dados da Associação Brasileira de Proteína Animal (ABPA, 2018), em 2017 a produção brasileira de carne de frango foi de 13,5 milhões de toneladas, mantendo o País na posição de maior exportador mundial e de segundo maior produtor de carne de frango, atrás apenas dos estados Unidos. Do total de frangos produzidos pelo País em 2017, 66,9\% foram destinados ao consumo interno e $33,1 \%$, para exportação. O consumo per capita em 2017, foi de $42,07 \mathrm{Kg} /$ ano e volume total de exportação foi de 4,3 milhões de toneladas? exportadas para mais de 150 países, com partici- pação de quase $40 \%$ no mercado mundial de carne de frango. O setor avícola industrial emprega mais de 5 milhões de pessoas, direta e indiretamente, e responde por quase 1,5\% do Produto Interno Bruto (PIB) nacional. Este setor é representado por milhares de produtores integrados, centenas de empresas beneficiadoras e dezenas de empresas exportadoras, o que ressalta sua importância para o País (ABPA, 2018).

Dentre os elos que mais absorvem novas tecnologias estão as agroindústrias que mantêm contato direto com os fornecedores de insumos e equipamentos em busca de novos processos ou novos equipamentos para melhorar o processo produtivo. Os fornecedores de equipamentos de alta tecnologia estão localizados, em sua maioria, na Europa e nos Estados Unidos, o que pode resultar em um gargalo tecnológico para a indústria (SANTINI, 2006).

Como forma de monitorar a evolução tecnológica e minimizar os altos custos e riscos de $\mathrm{P} \& \mathrm{D}$, as empresas mantêm parcerias com estes fornecedores e realizam parcerias em P\&D com universidades para testar produtos, visando complementar conhecimentos em áreas específicas de pesquisa (BASSI, SILVA e SANTOYO, 2013).

A necessidade de atender às exigências do mercado e a crescente pressão para se manterem competitivas no mercado fez com as empresas que compõem a cadeia produtiva de frangos de corte criassem seus próprios laboratórios de $\mathrm{P} \& \mathrm{D}$, para atenderem de forma mais rápida suas demandas e necessidades. Além disso, essas empresas criaram mecanismos de TT (Transferência de Tecnologia) na busca de novos parceiros e mercados. 
Este artigo analisa o processo de P\&D utilizado pelos segmentos de produção e industrialização da cadeia produtiva de frangos brasileiras. Trata-se de uma metodologia exploratória com uso de pesquisa bibliográfica, elaboração do referencial teórico e de entrevistas semiestruturadas junto a profissionais que atuam nos elos de agroindústrias, equipamentos, genética, nutrição e sanidade da cadeia produtiva de frangos de corte brasileira.

Este artigo está dividido em sete seções, iniciando com a parte introdutória, seguida das considerações sobre o papel da pesquisa no desenvolvimento tecnológico da cadeia produtiva de frangos de corte. A terceira seção aborda as mudanças tecnológicas na cadeia de frangos de corte brasileira, e a quarta descreve a cadeia produtiva de frangos de corte brasileira. A metodologia está descrita na quinta seção, seguida dos resultados e discussão, finalizando com as conclusões do trabalho.

\section{O papel da pesquisa no desenvolvimento tecnológico da cadeia produtiva de frangos de corte}

De acordo com Yeganiantz e Macedo (2002), a pesquisa agropecuária brasileira tem buscado contribuir para resolver os problemas sociais e promover novos conhecimentos, incorporando os avanços existentes e buscando a independência tecnológica do País, além de agilizar a transferência das informações, diminuindo o tempo entre a geração e a adoção de tecnologia. Todavia, segundo os autores, no caso da cadeia de aves, algumas autoridades em C\&T produtivo acreditam ser mais fácil e mais barato buscar tecnologia no exterior para aumentar a produtividade e qualidade dos produtos e serviços, em detrimento de um investimento consistente em pesquisa nacional.

No caso da cadeia produtiva de frangos de corte, até quatro décadas atrás, ela estava centrada em pequenas propriedades rurais e a sua produção era comercializada de forma direta para pequenos açougues (SANTOS, 2014). A partir dos anos 1970 ocorrem mudanças tecnológicas e na estrutura produtiva, destacando-se a redução do tempo de engorda das aves de corte; um grande avanço na seleção de linhagens; a intensificação do uso de rações balanceadas; o uso de equipamentos industriais de última geração e novas técnicas de manejo das aves, resultando em significativos ganhos de produtividade (ESPÍNDOLA, 2012).

Sorj, Pompermayer e Coradini (2008) relatam que a pesquisa e a produção tecnológica relacionadas principalmente ao material genético e insumos químico-veterinários sofisticados estão estreitamente ligadas ao capital internacional, sendo um dos elos básicos da internacionalização do complexo avícola. Considerando que na década de 1980 a indústria avícola nacional teve grande avanço graças a recursos investidos em P\&D interno às firmas, para Alves (2003), parece incoerente afirmar a ausência de pesquisas no setor; porém, pode-se afirmar que há ausência de pesquisas por parte das agências públicas de fomento e desenvolvimento.

Nesse contexto, Sorj, Pompermayer e Coradini (2008) destacam que a atuação do Estado nesse setor é essencialmente subsidiária e complementar. Sua atuação, no entanto, amplia-se em conjunto com as empresas integradoras, pela própria dinâmica do complexo avícola e pela importância que possui no conjunto das políticas oficiais. Mesmo que tenda a se intensificar, a ação do Estado se caracteriza por centrar-se na assistência técnica, ou seja, no acompanhamento da aplicação tecnológica e, num segundo plano, na adaptação da tecnologia já desenvolvida, atingindo apenas tangencialmente a pesquisa mais sofisticada.

Conforme consta no relatório do Ipardes (2002), a participação das Instituições Públicas de Pesquisa (IPPs) está mais voltada aos processos de manejo da produção agropecuária do que industrial, o que torna os resultados para a cadeia de aves bastante tímidos. De acordo com o relatório, há grande descolamento entre os interesses das instituições públicas e o setor produtivo, que pode ser explicitado por meio do atual processo de adoção de tecnologias.

$\mathrm{O}$ acelerado desenvolvimento científico e tecnológico impõe a necessidade de mudanças constantes, sendo o principal agente a Inovação Tecnológica. A busca pela inovação implica na escolha de trajetórias tecnológicas, uma vez que as empresas não saltam de um dado caminho para outro apenas com competências individuais (SILVEIRA et al., 2016). As fontes e direções de mudanças tecnológicas são definidas levando-se em conta o tamanho das empresas, o tipo de produto fabricado, os objetivos de inovação, as fontes de inovação e dos locais de inovação própria. A 
partir da escolha da trajetória tecnológica, a estratégia organizacional deve direcionar seu foco para prover um ambiente favorável à inovação (TIDD, BESSANT e PAVITT, 2008). O papel da inovação se tornou tão relevante que ultrapassa o ambiente das organizações, do segmento industrial ou setorial da economia e se expande para o ambiental nacional, no qual as políticas de Estado e governo são relevantes para impulsionar esse movimento. É o que se designa Sistema Nacional de Inovação - SNI (SILVEIRA et al., 2016).

Contribuem para o desenvolvimento tecnológico fatores como a trajetória tecnológica das empresas, o grau de oportunidade e apropriabilidade das inovações, além dos processos pelos quais os indivíduos e empresas aprendem e acumulam experiências para guiar o desenvolvimento tecnológico (SANTINI, 2006). Porém, devido à complexidade e características das atividades desenvolvidas, nem todos os elos da cadeia produtiva de frangos de corte têm o mesmo potencial para inovar.

Pesquisa realizada por Alves et al. (2006) demonstra que a indústria avícola inova continuamente por meio do elo processador, tanto em produto como em processo. Estudos do setor constataram que, no seu âmbito, a inovação é fundamentalmente incremental e adaptativa das tecnologias geradas no exterior para os diferentes elos da cadeia. A pesquisa demonstrou, ainda, que as patentes depositadas por detentores brasileiros são invenções de baixo grau tecnológico, compreendidas como mecanismos, dispositivos e adaptações em máquinas e equipamentos, caracterizando uma estratégia tecnológica geradora de baixos graus de apropriabilidade.

Em termos gerais, pode-se afirmar que os avanços da avicultura brasileira foram resultados da introdução de inovações nas áreas de genética, nutrição, sanidade e novos equipamentos no sistema criatório, o que possibilitou um ganho significativo na taxa de conversão alimentar. Estas inovações ocorreram em um primeiro momento, ocorreram por meio da aquisição de tecnologia importada via pacotes tecnológicos e, partir dessas aquisições, houve um processo de aperfeiçoamento e adaptação dessa tecnologia as condições brasileiras, resultando nesse avanço. Espíndola (2012) afirma que a capacidade de aprendizado tecnológico foi ainda impulsionada pela assimilação do conhecimento existente, do conhecimento tácito, da regulação estatal e dos incentivos governamentais.

\section{Mudanças tecnológicas na cadeia de frangos de corte brasileira}

De acordo com Jesus Junior et al. (2007), a cadeia produtiva de frangos de corte apresenta uma das trajetórias mais importantes dentre as cadeias produtivas agroindustriais brasileiras, marcada por constantes evoluções técnicas e tecnológicas, que resultaram na conquista do mercado interno e externo, superando os principais fornecedores avícolas mundiais.

As principais modificações ocorridas durante a década de 1980, segundo Mior (1992), estão relacionadas à mudança no padrão de consumo; ao acirramento da concorrência internacional; à estagnação do mercado nacional; à concentração de mercados e ao surgimento de novas tecnologias, que levaram à uma reestruturação agroindustrial, com o surgimento de grandes grupos agroindustriais ligados ao mercado externo. A partir dos anos 1980, devido à implantação do processo de qualidade total e da competição com mercados externos, houve um aumento da escala de produção, com redução da margem dos produtores e aumento da seletividade, excluindo os produtores mais pobres (BUAINAIN et al., 2007).

Os principais marcos na evolução tecnológica da avicultura mundial, de acordo com Schorr (1999), Rizzi (1993) e Santini (2006), estão resumidos no Quadro 1.

Quadro 1. Principais marcos na evolução tecnológica da avicultura mundial

\begin{tabular}{|c|c|c|}
\hline Década & Natureza & Evento \\
\hline $1950-1960$ & Genética & Cruzamentos/Híbridos \\
\hline $1960-1970$ & Sanidade & Programe/Profilaxia/Vacinas Linear \\
\hline $1970-1980$ & Nutrição & Instalações e Equipamentos \\
\hline $1980-1990$ & Manejo & Controle e Climatização \\
\hline $1990-2000$ & Meio Ambiente & \\
\hline
\end{tabular}

Fonte: Adaptado de Schorr (apud COELHO e BORGES, 1999), Rizzi (1993) e Santini (2006). 
Nos anos 1960, os programas de melhoramento genético avaliaram o número de ovos incubáveis e a taxa de eclosão. Já nas décadas de 1970 e 1980, a preocupação voltou-se para a conversão alimentar. A partir dos anos 1990, as pesquisas passaram a englobar as instalações de equipamentos, expressando preocupação com a redução de mão de obra e o bem-estar animal. Essas características foram ganhando importância com o aumento das exigências sanitárias, tanto em nível nacional como internacional, e as novas normativas voltadas para a preservação do meio ambiente. Atualmente, se observa uma forte tendência mundial de alterar o sistema de produção, abolindo os antibióticos utilizados como promotores de crescimento. Essa exigência está ligada à cobrança do consumidor por um alimento seguro e pelo bem-estar animal.

De acordo com Espíndola (2012), a carne de frango é hoje um dos principais alimentos que compõem a dieta humana. O aumento do consumo está relacionado ao preço e à máxima capacidade de transformação de cereais em carne no menor tempo possível de criação. Este último aspecto está diretamente associado aos processos de conversão alimentar, redução da idade de abate, peso médio, como demonstram os dados da Tabela 1.

O peso médio e a idade de abate reduziram entre 1960 e 2010 em 22,2\% e 26,8\%, enquanto que a conversão alimentar aumentou em 43,8\%. A genética, o manejo e a nutrição foram os principais responsáveis pelo ganho expressivo de produtividade na avicultura. Para melhor exemplificar as mudanças tecnológicas ocorridas no setor, serão apresentadas as inovações ocorridas nos três segmentos da cadeia de frango: produção, industrialização e comercialização/distribuição. Em relação à produção de insumos, três principais atividades responsáveis pelo fornecimento de matérias à indústria imperam: nutrição, sanidade e genética animal (SANTINI e SOUZA FILHO, 2004), assim como as empresas de equipamentos.

Os avanços na área de nutrição, de acordo com Santini (2006), têm contribuído para o desenvolvi- mento da genética avícola. As novas formulações estão diminuindo o tempo de crescimento das aves, além de melhorar seu desempenho. A proibição de uso coletivo de antibióticos, principalmente na União Europeia, tem feito com que a indústria de nutrição animal direcione suas pesquisas para novos produtos substitutivos como enzimas e probióticos.

As inovações tecnológicas na área de sanidade estão relacionadas com prebióticos, probióticos, acidificantes e enzimas. Os probióticos, como alternativa para as drogas tradicionais, as enzimas para incrementar a digestibilidade dos nutrientes da ração ou para diminuir os efeitos antinutricionais. O desenvolvimento de produtos para combater a coccidiose também foi apontado por Santini (2006) como uma área promissora na avicultura de corte.

A indústria de produtos veterinários tornou-se indispensável à produção de animais cada vez mais produtivos e livres de doenças e contaminações. Segundo Espíndola (2012), apesar do domínio das empresas multinacionais, ocorreu um esforço de empresas nacionais em desenvolverem ou importarem vacinas para a melhoria da sanidade do rebanho avícola brasileiro.

Em relação à genética, Santini (2006) destaca que a importação de material genético vem decaindo nos últimos anos no Brasil, pois o País está multiplicando o material genético internamente. Estudos indicam que $80 \%$ das melhorias obtidas nas linhagens decorreram do processo de seleção, instalação, manejo, nutrição, ambiente e sanidade. Na opinião de Espíndola (2012), a trajetória do progresso técnico caminhará em direção de um aprofundamento da busca do genoma da galinha e do seu possível mapeamento. O melhoramento genético está centrado nas características e na maximização da produção de carne de alta qualidade com o mínimo de custos de produção.

A indústria de equipamentos avícolas vem implantando diversas inovações em processos e produtos que buscam o aumento da produtividade. Segundo Espíndola (2012), as inovações ocorreram igualmente

Quadro 2. Índices de produtividade da avicultura de corte (mundo)

\begin{tabular}{lcccccc}
\hline \multicolumn{1}{c}{ Índices de produtividade } & $\mathbf{1 9 6 0}$ & $\mathbf{1 9 6 5}$ & $\mathbf{1 9 8 5}$ & $\mathbf{2 0 0 5}$ & $\mathbf{2 0 1 0}$ & $\mathbf{1 9 6 0 / 2 0 1 0}$ \\
\hline Peso médio vivo (kg) & 1,60 & 1,6 & 1,9 & 2,4 & 2,30 & $-22,2 \%$ \\
Conversão Alimentar (kg/ração) & 2,25 & 2,4 & 2,0 & 1,7 & 1,75 & $43,8 \%$ \\
Idade média ao abate (dias) & 56 & 63 & 49 & 42 & 41 & $-26,8 \%$ \\
\hline
\end{tabular}

Fonte: Adaptado de Espíndola (2012) e Costa et al. (2015). 
em relação às instalações para controlar as condições adversas do clima, como equipamentos de climatização (ventiladores, umificadores, aquecedores, cortinas isolantes ou sistema de túnel), controlados por softwares. Na região Centro-Oeste existem aviários com túnel de ventilação, nebulizadores de água e sistema de recirculação de água em painéis de evaporação. Nas regiões Sul e Sudeste, a tendência é a de adaptações nos aviários convencionais e semiautomatizados para atender às necessidades de conforto térmico das aves. Todas essas melhorias foram acompanhadas por um programa de rastreabilidade, que consiste na obtenção de dados, desde a origem da ração, pintinhos e medicamentos até o produto final. O resultado é apresentado ao consumidor por um selo com uma etiqueta numérica que permite estabelecer todas as fases de produção (ESPINDOLA, 2012).

No segmento de industrialização se observa o desenvolvimento de produtos com valor agregado e de qualidade. As empresas estão reduzindo a exportação de frangos inteiros e aumentando a exportação de cortes. O crescimento das empresas em termos produtivos e comerciais é atribuído por Santini (2006) às estratégias de expansão produtiva e à melhoria da produtividade, com uso de novas tecnologias e novas instalações, além da reestruturação organizacional. As tecnologias de controle automático de temperatura, umidade, fornecimento de água e ração resultaram no aumento do coeficiente alimentar dos frangos. Incubadoras e nascedouros equipados eletronicamente permitem o controle do desenvolvimento da ave (SANTINI, 2006).

Quanto ao segmento de comercialização e distribuição, Sorj, Pompermayer e Coradini (2008) afirmam que a exportação brasileira de frangos deve ser entendida como um novo tipo de exportação de produtos, diferente do modelo exportador tradicional que se baseava na utilização extensiva de terra e força de trabalho. As exportação avícola tem como fundamento um moderno complexo agroindustrial crescentemente interiorizado, e como centro impulsionador central o próprio mercado interno.

De acordo com Jesus Junior et al. (2007), a grande expansão da produção e exportação de frangos levou as maiores indústrias do setor a buscarem a internacionalização de suas operações, construindo novas plantas ou adquirindo plantas já existentes. Essa estratégia objetiva diminuir o risco de eventuais barreiras comerciais que possam ser impostas por esses merca- dos, além de propiciar maior proximidade dos mercados consumidores. Em relação aos aspectos logísticos de escoamento da produção do setor, os autores destacam dificuldades, principalmente na cadeia de frios e no sistema rodoviário de transporte, o que em geral é comum em quase todos os setores da economia. Os autores ressaltam que os aspectos destas ineficiências são sentidos com maior intensidade pelo segmento exportador.

Para Rodrigues (2007), a posição conquistada pelo Brasil como maior exportador mundial de carne de frango se deve a uma tríade básica: status sanitário, custo baixo e diferenciação pela qualidade. Essa combinação de fatores confere à carne de frango brasileira qualidade superior frente à dos demais competidores.

Apesar dos grandes avanços tecnológicos, observa-se, ainda, uma forte dependência da avicultura industrial nacional em relação aos fornecedores de tecnologias estrangeiros. A competitividade da avicultura brasileira pode estar hoje baseada em fatores não tecnológicos, como o custo relativo da mão de obra e a alta produtividade de grãos. Esse fato é preocupante, uma vez que se percebe que as futuras trajetórias tecnológicas para o setor estão baseadas significativamente em áreas complexas do conhecimento científico (ALVES, 2003; SANTINI, 2006).

Segundo Santini (2006), como produtores de tecnologia, empresas norte-americanas e europeias detêm maior e melhor competência relativa em algumas áreas, como melhoramento genético, onde o Brasil ainda é vulnerável. Desta forma, seria estratégico ampliar a pesquisa das instituições públicas, buscando maior desenvolvimento tecnológico em parceria com as empresas dos diversos elos da cadeia. Esta parceria não deve se limitar á área de genética, mas também de sanidade e de nutrição animal, instalações e equipamentos das plantas industriais, no intuito de gerar outras fontes de competitividade dinâmica da avicultura industrial brasileira.

\section{A cadeia produtiva de frango de corte brasileira}

A avicultura industrial brasileira surgiu no final da década de 1950, quando novos aviários começaram a ser estruturados, utilizando novos métodos de manejo, ao mesmo tempo em que se iniciou uma intensa atua- 
ção dos institutos de pesquisa no sentido de melhorar o combate às doenças e o controle sanitário em geral, junto ao surgimento das primeiras associações de avicultores e cooperativas (SORJ, POMPERMAYER e CORADINI, 2008). A partir da década de 1980, a cadeia de frangos de corte apresentou significativa transformação, com ganhos de produtividade, abertura de novos mercados e pela consolidação da organização da cadeia, com maior integração entre seus elos (SILVA e SAES, 2005a).

As grandes modificações no sistema produtivo, como o alto nível tecnológico e a integração avicultor/ agroindústria, deram maior dinamismo à atividade, colocando-a em posição privilegiada em relação a outras atividades pecuárias no Brasil. Para os produtores, esse sistema garante o escoamento da sua produção e assistência técnica, obtenção de melhores insumos de produção, assegura produção ininterrupta, propicia maior facilidade de acesso ao crédito e a incorporação mais rápida de inovações tecnológicas (OLIVEIRA et al., 2015).

De acordo com a Embrapa Suínos e Aves (2013), na década de 1990, a cadeia passou para a era da com- petitividade, em que a reestruturação tecnológica, a eficiência, a diminuição dos custos e a reestruturação administrativa das empresas transformaram-se em estratégias de sobrevivência. Neste período, a avicultura buscou novos mercados, oferecendo produtos de maior valor agregado. A conquista do mercado externo veio com a comprovação da qualidade sanitária dos rebanhos. Por outro lado, a expressiva melhoria de renda da população brasileira, nos últimos anos, vem impulsionando o consumo interno do produto (EMPRESA BRASILEIRA..., 2013).

A avicultura tem colocado o Brasil em destaque mundial, devido, principalmente a organização, o uso de tecnologia e capacidade gerencial do setor, que têm sido exemplos de sucesso para as demais cadeias de carnes.

\subsection{A organização da cadeia produtiva de frangos de corte}

Segundo Voilà e Triches (2013) e Silva e Saes (2005b), a cadeia produtiva de frango é caracterizada por uma sequência de operações que pode ser dividida em três grandes áreas (Figura 1).

Figura 1. Cadeia produtiva de frangos de corte

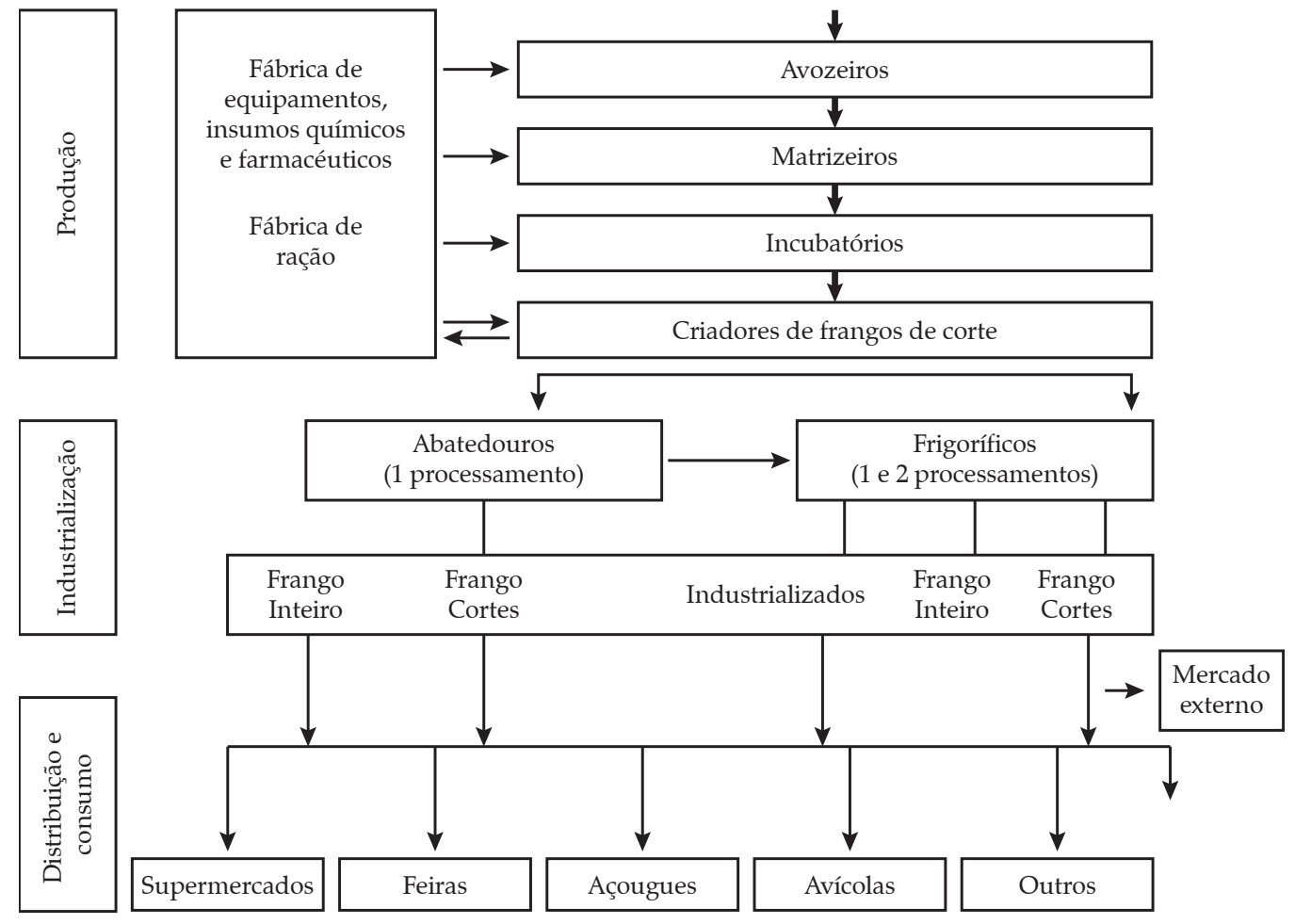

Fonte: Adaptado de Mendes, Nass e Macari (2004) e Violá e Triches (2013). 
- Produção de insumos: a etapa de produção de insumos compreende os avozeiros, matrizeiros, incubatório e aviários. Os avozeiros importam os ovos das linhagens avós que produzem as matrizes, nos matrizeiros, que gerarão os pintinhos comerciais. A incubação dos ovos das matrizes é realizada nos incubatórios. Os pintinhos com um dia de idade são entregues ao criador de frangos, a maior parte, de empresas integradoras ou cooperativas (SILVA e SAES, 2005b). Neste elo estão as empresas de sanidade, nutrição, genética e equipamentos, principais fornecedores de insumos e principais elos inovadores da cadeia.

- Industrialização: desenvolvida por uma agroindústria ou frigorífico. Se inicia a partir do abate do frango, com idade média de 42 dias, que, depois de abatido, será vendido inteiro, em partes, ou, ainda, processado como pratos rápidos ou embutidos, o que agrega mais valor ao seu preço e permite um processo de diferenciação do produto (SILVA e SAES, 2005b). Nesta área, encontram-se as agroindústrias, que absorvem as inovações produzidas pelas empresas que fazem parte da etapa da produção (anteriormente mencionada).

- Comercialização e distribuição: a etapa de comercialização/distribuição compreende empresas atacadistas, redes de supermercados, açougues, varejistas e mercado internacional (VIOLÁ e TRICHES, 2013).

Durante o processo de produção, industrialização e distribuição do produto final, estão presentes outros setores geradores e fornecedores de tecnologia, pesquisa e desenvolvimento genético, equipamentos, medicamentos, rações e insumos e transportes que completam a cadeia produtiva de frangos de corte. A avicultura não se limita à produção de carnes, mas em um grande complexo que vai desde o planejamento da produção até a comercialização dos produtos finais.

Uma pesquisa realizada por Alves (2003) identificou os principais elos inovadores da cadeia produtiva de frangos de corte. Parte significativa dos ganhos produtivos da agroindústria avícola depende do desenvolvimento tecnológico gerado por estes elos (Figura 2).

Os principais polos geradores de inovações tecnológicas avícolas, assim como os esforços em P\&D, estão nas etapas de produção e industrialização, em que estão localizadas as empresas de nutrição, genética, sanidade, máquinas e equipamentos e agroindústrias. Por essa razão esses elos foram escolhidos como objeto do presente estudo.

No campo da genética, grandes empresas estrangeiras controlam o mercado mundial de genética avícola e estabelecem intensa competição, tornando o

Figura 2. Principais elos geradores de inovações na cadeia da avicultura

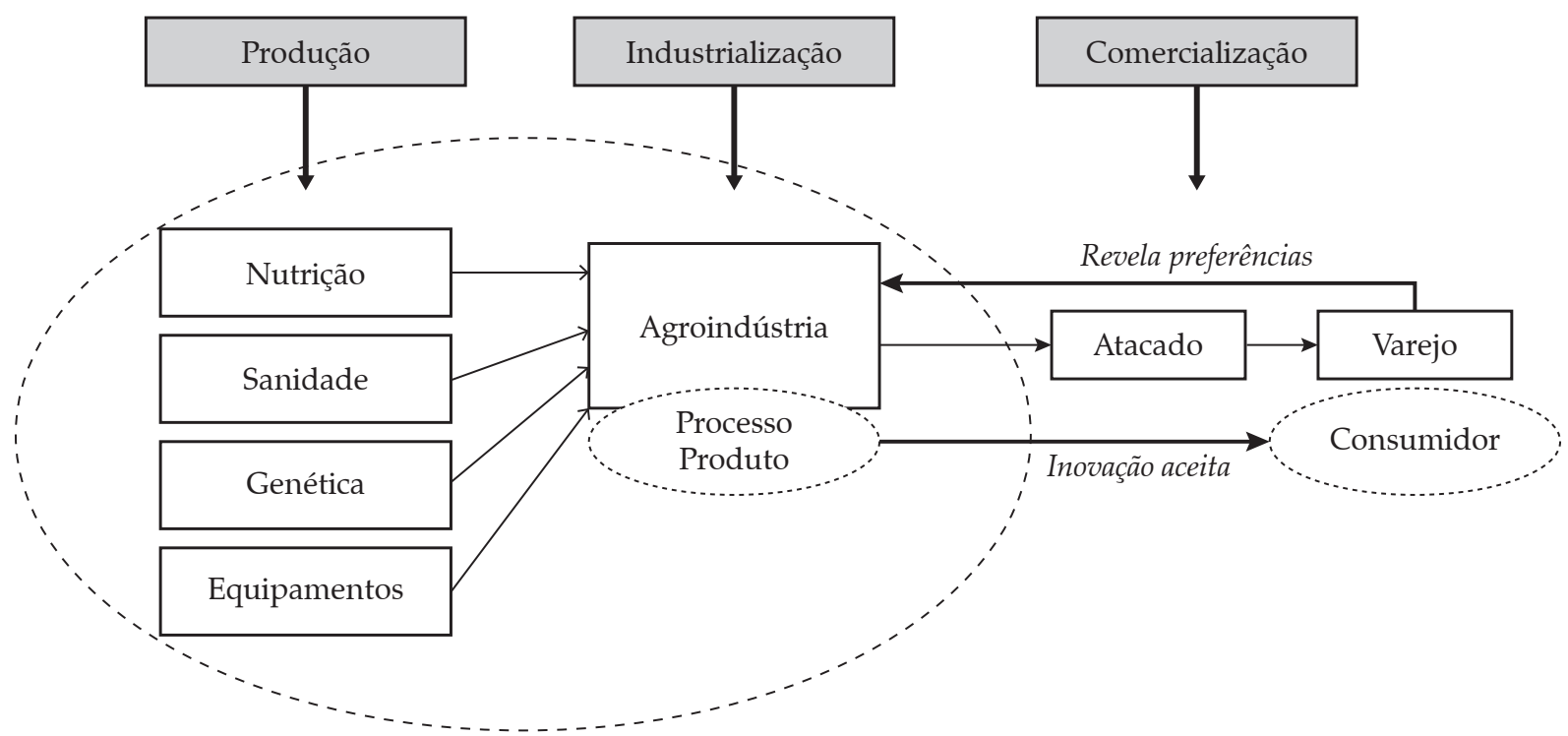

Fonte: Alves (2003). 
mercado dinâmico e com fortes barreiras à entrada (ALVES, 2003).

O segmento fornecedor de máquinas e equipamentos também é dominado por poucas empresas que atuam ainda em outros segmentos. As inovações geradas nos elos de produção são na maior parte, direcionadas e absorvidas pelo setor de industrialização (agroindústrias), que por sua vez, inova principalmente em processos (de custos e de tempo) e produtos, que são repassados ao consumidor.

Jesus Junior et al. (2007) afirmam que, longe de ser confusa, a produção de frangos envolve tantas e tão diversas atividades exigindo tal grau de congruência entre si que poderia ser comparada à uma engrenagem de relógio, em que cada peça é fundamental para manter a precisão necessária para o alcance do seu objetivo final: a constância da oferta de carne de frango aos mercados consumidores nacional e internacional. Nessa cadeia, a agroindústria exerce a função de empresa focal ${ }^{6}$, sendo a principal responsável por coordenar os elos de produção, de matéria-prima e distribuição por meio de sistemas de integração (VIOLÁ e TRICHES, 2013).

\section{Metodologia}

Para atingir o objetivo desse trabalho, optou-se por uma pesquisa qualitativa de caráter exploratório e descritivo. A característica exploratória, expressa a necessidade de familiarizar-se com os critérios ainda pouco explorados do processo. As pesquisas exploratórias, segundo Marconi e Lakatos (2007), aumentam a familiaridade do pesquisador com um ambiente, fato ou fenômeno, para a realização de uma pesquisa mais detalhada no futuro, modificar ou propor novos conceitos. O caráter descritivo está na busca por aspectos gerais e amplos de um contexto social, que possibilitam o desenvolvimento de uma análise para identificar as diferentes formas dos fenômenos, bem como as variáveis que influenciam ou causam o aparecimento dos fenômenos abordados. De acordo com Oliveira (2002), é considerado o tipo de estudo mais adequado para entender o comportamento de vários fatores e elemen-

6. A empresa focal estabelece regras ou governa a cadeia de suprimento, mantém contato direto com o consumidor ou projeta os produtos que a cadeia oferece (CARVALHO e BARBIERI, 2013). tos que influenciam determinados fenômenos em um determinado período de tempo.

Quanto aos procedimentos, foram realizadas pesquisas bibliográficas e documentais e a aplicação de questionários semiestruturados. Os questionários foram aplicados a 142 agentes que atuam nos elos de agroindústria, equipamentos, genética, nutrição e sanidade. Os agentes que participaram da entrevista foram selecionados a partir do cadastro das empresas e entidades ligadas à cadeia produtiva de frangos de corte do Guia Gessulli de avicultura industrial, disponível no site: http://www.guiagessulli.com.br/. Além desse cadastro, foi buscado junto aos pesquisadores da área de avicultura da Embrapa Suínos e Aves sugestões de pessoas que poderiam contribuir de forma significativa para a pesquisa.

Os segmentos de produção e de industrialização da cadeia produtiva de frangos de corte foram escolhidos devido ao fato de serem os elos da cadeia que mais inovam. A população, de acordo com Malhotra (2012), é a totalidade dos elementos que possuem algum conjunto comum de características de interesse para um determinado estudo. Ela pode ser compreendida como o "[...] o universo para o qual o pesquisador pretende generalizar os resultados da pesquisa" (FERRARESI, 2010 , p. 74). No caso dessa pesquisa, o número de elementos desta população é elevado, sendo necessário reduzir o número de elementos para caracterizar uma amostra (MARCONI e LAKATOS, 2007).

$\mathrm{O}$ tipo de amostragem selecionado para a pesquisa foi a aleatória simples, na qual todos os elementos têm a mesma probabilidade de serem selecionados. Santos (2014) indica que o cálculo da amostra aleatória simples é dado pela fórmula:

$$
n=\frac{N \cdot z^{2} \cdot p(1-p)}{z^{2} \cdot p(1-p)+e^{2} \cdot(N-1)}
$$

$n$ : amostra calculada;

$N$ : população;

$z$ : variável normal padronizada associada ao nível de confiança;

p: probabilidade do evento;

$e$ : erro amostral.

Para a escolha dos atores junto aos diversos elos da cadeia, o erro amostral atribuído para o cálculo foi $5 \%$, com um nível de confiança de $95 \%$ para uma população de 190 pessoas. Nesse caso, o número da amos- 
tra desejada é de 128. O número de respondentes foi de 142, superior ao desejado. A população foi dividida em cinco elos da cadeia: agroindústrias, equipamentos, genética, nutrição e sanidade. O número de atores de cada elo cada variou de acordo com o número de empresas selecionadas a partir do cadastro utilizado. A população e o número de questionários enviados e respondidos em cada elo foram: Sanidade $38(22)^{7}$; Nutrição 66(52); Genética 13(12); Equipamentos 37(29); Agroindústrias 36(27).

Em relação às empresas de atuação dos entrevistados, 50,3\% têm atuação internacional e 35\% dessas empresas são de grande porte (com mais de 500 empregados). Quanto ao perfil dos entrevistados, $54,54 \%$ eram gerentes, $20,20 \%$ eram diretores ou presidentes e os demais eram analistas $(6,6 \%)$ e técnicos $(20,20 \%)$.

As questões versavam sobre: Fontes e instrumentos utilizados na busca de inovação, existência de um processo de PD\&I estruturado, tipo de pesquisa realizada, principais parceiros e critérios de escolha dos parceiros. Os questionários foram enviados utilizando-se o programa Lime Survey, no período de 20 de novembro a 30 de dezembro de 2014.

As análises estatísticas foram realizadas por meio dos softwares IBM SPSS (Statistical Package for the Social Sciences) v. 21, IBM SPSS Amos v. 21.0.0 e Microsoft Excel nas etapas de avaliação dos dados coletados. Na tentativa de atribuir maior credibilidade nas respostas obtidas por meio da aplicação dos questionários de validação do modelo, foi aplicado o teste de hipótese denominado Qui-quadrado.

\section{Resultado e discussão}

A mudança tecnológica é baseada no investimento e na utilização de equipamentos e insumos desenvolvidos e fabricados por fornecedores (SEREIA, 2012). Geralmente as empresas fazem pouca P\&D de ponta. A maioria das inovações ocorre em processos e objetiva reduzir custos.

As fontes de inovação das empresas variam de acordo com as atividades desenvolvidas e, muitas vezes, essas fontes são também parceiras na busca da

7. Os números fora dos parênteses equivalem ao número de questionários enviados, e os valores entre parênteses representam a quantidade de respondentes. inovação. As agroindústrias são usuárias de inovações desenvolvidas em outros setores, o que explica porque suas principais fontes de inovação são as universidades nacionais e os fornecedores, nacionais e estrangeiros (Tabela 1).

Apesar do fato de que os fornecedores são a principal fonte na busca de inovação pelos elos de equipamento e agroindústrias, os resultados chamam a atenção para a importância das universidades nacionais e estrangeiras e IPPs nesse processo, principalmente nos elos de nutrição e sanidade.

Considerando-se a complexidade do sistema brasileiro de pesquisa agropecuária, com a participação de diversas instituições federais, estaduais, de ensino superior, instituições sem fins lucrativos e companhias privadas engajadas nesse esforço, a pesquisa agropecuária brasileira ainda é, predominantemente, uma atribuição do setor público (BEINTEMA et al., 2001). De forma geral, há um reconhecimento por parte do setor privado pelo esforço das instituições públicas em contribuir para o desenvolvimento da cadeia.

As empresas utilizam-se de instrumentos para captar informações sobre as inovações que ocorrem em sua área de atuação. Esses instrumentos são variados e dependem do objetivo e das condições de alcance dessas empresas (Tabela 2).

Dentre os instrumentos utilizados destacam-se as parcerias em P\&D, as publicações científicas e congressos, mais amplamente utilizados pelos elos de genética, nutrição, sanidade. Cabe ressaltar que as características desses instrumentos são de cunho científico e inovador, comprovando a busca por informações inovadoras e cientificamente comprovadas, característico de um processo de $\mathrm{P} \& \mathrm{D}$.

Por outro lado, as agroindústrias que estão mais voltadas para as demandas do consumidor consideram as feiras como seu principal instrumento na busca de inovações, o que corrobora com a literatura, uma vez que sua principal meta são produtos que atendam essas demandas.

Em relação ao processo de $\mathrm{P} \& \mathrm{D}$, a maior parte das empresas pesquisadas conta com um processo estruturado, com laboratórios e equipe especializada, conforme consta na Tabela 3.

Os elos de equipamentos e agroindústrias são os que apresentam o menor número de empresas com P\&D estruturado. Em contrapartida, nos elos de Genética, Nutrição e Sanidade a maioria das empresas desenvolve 
atividades de pesquisa e/ou desenvolvimento. Esses resultados corroboram a teoria de Tidd, Bessant e Pavit (2008), sobre a agroindústria ser o elo que "absorve" as tecnologias e inovações geradas nos demais elos.
Dentre as empresas que desenvolvem pesquisa, as atividades mais realizadas são teste de produto, desenvolvimento de novos produtos e de novos processos, conforme demonstrado na Tabela 4 .

Tabela 1. Fontes de inovação da cadeia produtiva de frangos de corte

\begin{tabular}{lccccc}
\hline \multirow{2}{*}{ Fontes de inovação } & \multicolumn{5}{c}{ Elos } \\
\cline { 2 - 5 } & Agroindústrias & Equipamentos & Genética & Nutrição & Sanidade \\
\hline Concorrentes & $51,8 \%$ & $50,00 \%$ & $8,30 \%$ & $13,70 \%$ & $4,50 \%$ \\
Cliente/Consumidor & $22,22 \%$ & $72,40 \%$ & $41,70 \%$ & $49,00 \%$ & $40,90 \%$ \\
Universidade estrangeira & $18,52 \%$ & $14,30 \%$ & $83,30 \%$ & $63,30 \%$ & $84,20 \%$ \\
Universidade nacional & $70,37 \%$ & $26,90 \%$ & $75,00 \%$ & $76,50 \%$ & $83,30 \%$ \\
Produtores & $22,22 \%$ & $44,40 \%$ & $8,30 \%$ & $9,80 \%$ & $13,60 \%$ \\
Técnicos & $33,33 \%$ & $44,40 \%$ & $41,70 \%$ & $35,30 \%$ & $13,60 \%$ \\
IPPs & $51,84 \%$ & $27,60 \%$ & $50,00 \%$ & $54,90 \%$ & $77,80 \%$ \\
Fornecedores estrangeiros & $81,48 \%$ & $48,30 \%$ & $83,30 \%$ & $41,20 \%$ & $22,20 \%$ \\
Fornecedores nacionais & $85,19 \%$ & $65,50 \%$ & $50,00 \%$ & $37,30 \%$ & $27,30 \%$ \\
\hline
\end{tabular}

Fonte: Dados da pesquisa.

Tabela 2. Principais instrumentos na busca por inovação tecnológica

\begin{tabular}{lccccc}
\hline \multirow{2}{*}{ Instrumentos de inovação } & \multicolumn{4}{c}{ Elos } \\
\cline { 2 - 6 } & Agroindústria & Equipamento & Genética & Nutrição & Sanidade \\
\hline Parcerias em P\&D & $51,85 \%$ & $41,40 \%$ & $75,00 \%$ & $52,90 \%$ & $77,30 \%$ \\
Publicação técnica & $48,15 \%$ & $58,60 \%$ & $50,00 \%$ & $52,90 \%$ & $59,10 \%$ \\
Publicação científica & $40,74 \%$ & $24,10 \%$ & $75,00 \%$ & $75,50 \%$ & $84,20 \%$ \\
Visitas internacionais & $55,56 \%$ & $20,70 \%$ & $91,70 \%$ & $43,10 \%$ & $50,00 \%$ \\
Benchmarking & $51,85 \%$ & $24,10 \%$ & $50,00 \%$ & $25,50 \%$ & $18,20 \%$ \\
Exposições & $51,85 \%$ & $41,40 \%$ & $41,70 \%$ & $21,00 \%$ & $9,10 \%$ \\
Congressos & $70,37 \%$ & $37,90 \%$ & $83,30 \%$ & $74,50 \%$ & $50,00 \%$ \\
Feiras & $81,48 \%$ & $51,70 \%$ & $50,00 \%$ & $37,30 \%$ & $30,00 \%$ \\
Consultorias & $62,96 \%$ & $10,30 \%$ & $58,30 \%$ & $29,40 \%$ & $42,10 \%$ \\
\hline
\end{tabular}

Fonte: Dados de pesquisa.

Tabela 3. Estrutura própria de P\&D

\begin{tabular}{lc}
\hline \multicolumn{1}{c}{ Elos } & Estrutura de P\&D \\
\hline Agroindústria & $55,56 \%$ \\
Equipamento & $58,62 \%$ \\
Genética & $75,00 \%$ \\
Nutrição & $80,40 \%$ \\
Sanidade & $68,20 \%$ \\
\hline
\end{tabular}

Fonte: Dados de pesquisa.

Tabela 4. Atividades de P\&D realizadas pelas empresas

\begin{tabular}{lcccc}
\hline \multirow{2}{*}{ Elo } & \multicolumn{4}{c}{ Principais Atividades de P\&D } \\
\cline { 2 - 5 } & $\begin{array}{c}\text { Adaptação de produtol } \\
\text { processo estrangeiros }\end{array}$ & $\begin{array}{c}\text { Teste de } \\
\text { produto }\end{array}$ & $\begin{array}{c}\text { Desenvolvimento } \\
\text { novos produtos }\end{array}$ & $\begin{array}{c}\text { Desenvolvimento } \\
\text { novos processos }\end{array}$ \\
\hline Agroindústrias & $83,30 \%$ & $100 \%$ & $91,70 \%$ & $83,30 \%$ \\
Equipamentos & $17,65 \%$ & $70,59 \%$ & $100 \%$ & $58,82 \%$ \\
Genética & $22,20 \%$ & $100 \%$ & $88,90 \%$ & $11,10 \%$ \\
Nutrição & $26,80 \%$ & $80,50 \%$ & $97,60 \%$ & $46,90 \%$ \\
Sanidade & $37,50 \%$ & $75 \%$ & $87,50 \%$ & $62,50 \%$ \\
\hline
\end{tabular}

Fonte: Dados de pesquisa. 
As agroindústrias desenvolvem $\mathrm{P} \& \mathrm{D}$ para testar e desenvolver novos produtos e processos e também para adaptar produtos e processos adquiridos no exterior (como já mencionado), sempre voltado para o atendimento das demandas do mercado.

Por outro lado, os elos de equipamentos, genética, nutrição e sanidade buscam o desenvolvimento de novos produtos e em escala menor, o teste de produtos, atividade típicas de um setor intensivo de P\&D.

As atividades de P\&D são desenvolvidas em parceria com outras instituições, públicas ou privadas, principalmente nas empresas de genética e sanidade, em que $100 \%$ das empresas pesquisadas afirmam manter parcerias para o desenvolvimento de P\&D (Tabela 5).

Os resultados demonstram que a parceria em $P \& D$ é uma atividade fortemente presente nos elos de produção e industrialização da cadeia produtiva de frangos de corte.

Essa forte parceria é um fator muito positivo, principalmente quando se trata de parcerias público-privadas, que têm sido amplamente estimuladas pelo governo, no intuito de reduzir custos financeiros e humanos.

Esses resultados corroboram a visão de Nascimento e Labiak Junior (2011), que afirmam que nenhum desenvolvimento ou inovação são fruto de esforço solitário, o que faz com que as empresas desenvolvam uma dinâmica de cooperação com outras instituições como universidades, IPPs etc., na tentativa de ultrapassar suas limitações e partilhar riscos de inovação.

As empresas pesquisadas mantêm parcerias em P\&D com diferentes tipos de parceiros, principalmente as empresas de genética e agroindústrias. Todas as agroindústrias, empresas de genética e sanidade citaram como principais parceiros os especialistas, os fornecedores e as universidades, nacionais e internacionais (Tabela 6).

Nos elos de equipamentos e nutrição, as empresas são mais seletivas na busca de parceiros. O elo de equipamento prefere firmar parcerias com as IPPs e fornecedores nacionais, enquanto que o de nutrição prefere parcerias com universidades públicas e estrangeiras. Nos demais elos, as parcerias são feitas com diversos agentes e instituições. A escolha dos parceiros está relacionada ao tipo de pesquisa realizada pelas empresas; todavia, essa questão não foi abordada no presente trabalho.

Os critérios de escolha de parceiros para realização de P\&D também variam de acordo com os objetivos e valores de cada empresa. A credibilidade, confiança, conhecimento e competência são os critérios mais valorizados pelas empresas pesquisadas (Tabela 7).

Tabela 5. Parcerias em P\&D

\begin{tabular}{lcc}
\hline \multirow{2}{*}{ Elos } & \multicolumn{2}{c}{ Parcerias em P\&D } \\
\cline { 2 - 3 } & Sim & Não \\
\hline Agroindústrias & $81,80 \%$ & $12,20 \%$ \\
Equipamentos & $81,80 \%$ & $12,20 \%$ \\
Genética & $100 \%$ & $0 \%$ \\
Nutrição & $95,90 \%$ & $4,10 \%$ \\
Sanidade & $100 \%$ & $0 \%$ \\
\hline
\end{tabular}

Fonte: Dados de pesquisa.

Tabela 6. Principais parceiros em P\&D das empresas

\begin{tabular}{lccccc}
\hline \multirow{2}{*}{ Principais parceiros em P\&D } & \multicolumn{5}{c}{ Elos } \\
\cline { 2 - 5 } & Agroindústrias & Equipamentos & Genética & Nutrição & Sanidade \\
\hline Especialistas estrangeiros & $100 \%$ & $5,90 \%$ & $100 \%$ & $25,50 \%$ & $100 \%$ \\
Especialistas nacionais & $100 \%$ & $5,90 \%$ & $100 \%$ & $21,30 \%$ & $100 \%$ \\
Fornec. estrangeiros & $100 \%$ & $11,80 \%$ & $100 \%$ & $38,30 \%$ & $100 \%$ \\
Fornec. nacionais & $100 \%$ & $47,10 \%$ & $100 \%$ & $34,00 \%$ & $100 \%$ \\
IPPs estrangeiros & $100 \%$ & $5,90 \%$ & $100 \%$ & $48,90 \%$ & $95,20 \%$ \\
IPPs nacionais & $100 \%$ & $52,90 \%$ & $100 \%$ & $34,00 \%$ & $100 \%$ \\
Univ. estrangeiras & $100 \%$ & $5,90 \%$ & $100 \%$ & $51,10 \%$ & $90,50 \%$ \\
Univ. nacionais & $100 \%$ & $23,30 \%$ & $100 \%$ & $89,60 \%$ & $100 \%$ \\
\hline
\end{tabular}

Fonte: Dados de pesquisa. 
Tabela 7. Critérios para escolha dos parceiros em P\&D

\begin{tabular}{lccccc}
\hline \multirow{2}{*}{ Critérios de escolha } & \multicolumn{5}{c}{ Elos } \\
\cline { 2 - 5 } & Agroindústrias & Equipamentos & Genética & Nutrição & Sanidade \\
\hline Capacidade de inovação & $50 \%$ & $64,70 \%$ & $27,30 \%$ & $51,10 \%$ & $76,20 \%$ \\
Agilidade & $60 \%$ & $47,10 \%$ & $63,60 \%$ & $57,40 \%$ & $25,00 \%$ \\
Baixo nível de burocracia & $65 \%$ & $35,30 \%$ & $54,50 \%$ & $25,50 \%$ & $47,60 \%$ \\
Competência & $75 \%$ & $64,70 \%$ & $54,50 \%$ & $61,70 \%$ & $71,40 \%$ \\
Confiança & $85 \%$ & $41,20 \%$ & $90,90 \%$ & $72,30 \%$ & $71,40 \%$ \\
Conhecimento & $90 \%$ & $82,40 \%$ & $72,70 \%$ & $80,90 \%$ & $90,50 \%$ \\
Credibilidade & $90 \%$ & $70,60 \%$ & $90,90 \%$ & $85,10 \%$ & $85,70 \%$ \\
RH e financeiros & $55 \%$ & $23,50 \%$ & $18,20 \%$ & $17,00 \%$ & $23,80 \%$ \\
Estrutura de P\&D & $65 \%$ & $41,20 \%$ & $63,60 \%$ & $63,80 \%$ & $61,90 \%$ \\
Interesse & $25 \%$ & $29,40 \%$ & $45,50 \%$ & $31,90 \%$ & $4,20 \%$ \\
Mercado & $10 \%$ & $11,80 \%$ & $18,20 \%$ & $17,00 \%$ & $4,80 \%$ \\
Presença mundial & $10 \%$ & $36,40 \%$ & $14,90 \%$ & $9,50 \%$ & $9,50 \%$ \\
Proximidade física & $30 \%$ & $17,60 \%$ & $0 \%$ & $6,40 \%$ & $14,30 \%$ \\
Rede relacionamento & $5 \%$ & $50 \%$ & $9,10 \%$ & $19,10 \%$ & $14,30 \%$ \\
\hline
\end{tabular}

Fonte: Dados de pesquisa.

Considerando-se a competição acirrada, característica própria dessa cadeia, é compreensível esse resultado. Em um setor fortemente competitivo, esses critérios são imprescindíveis em uma parceria. A confiança, citada como um critério importante na escolha dos parceiros pelos elos pesquisados, corrobora a opinião de autores como Nascimento e Labiak Jr (2011), Knorringa e Meyer-Stamer (1998), Santoro e Gopalakrishnan (2001).

A grande oportunidade de alavancar o processo de P\&D na cadeia estudada está nas parcerias entre os setores público e privado. E os maiores benefícios referem-se ao compartilhamento da infraestrutura física e do capital humano. As instituições públicas (universidades e os IPPs) contam com equipes multidisciplinares, que dificilmente poderiam ser mantidas pelo setor privado, mas que possibilitam uma aborda- gem mais ampla do que a possível de ser executada por grupos de pesquisadores do setor privado, mais direcionados à solução de demandas específicas.

Os investimentos em P\&D na cadeia produtiva resultam em novas tecnologias que proporcionam diversos benefícios ao setor, incluindo as empresas, produtores e consumidores, com equipamentos a custos mais compatíveis, aumento da produtividade e qualidade da produção, resultando em produtos mais baratos e de maior qualidade.

Para atribuir maior credibilidade nas respostas obtidas nessa pesquisa, foi aplicado o teste de hipótese Qui-quadrado, que avalia a associação existente entre as variáveis qualitativas. Para isso, foram selecionadas algumas variáveis, que foram aplicadas ao teste, cujo resultado está demonstrado no Quadro 3.

Quadro 3. Associação entre variáveis qualitativas pelo método qui-quadrado

\begin{tabular}{|l|c|}
\hline \multicolumn{1}{|c|}{ Variáveis testadas } & Resultado \\
\hline Fontes de Inovação (IPPs) X Instrumentos utilizados na busca de inovação (Publicações científicas) & 0,0000011 \\
\hline Fontes de Inovação (concorrentes) X Instrumentos utilizados na busca de inovação (Benchmarking) & 0,007666 \\
\hline Parceiro (IPPs) X Atividade de P\&D (Teste de produtos) & 0,0000000 \\
\hline Parceiro (IPPs) X Atividade de P\&D (novos produtos) & 0,2618077 \\
\hline Parceiro (fornecedores nacionais) X Atividade de P\&D (novos produtos) & 0,0024466 \\
\hline Parceiro (IPPs) X Critério de escolha do parceiro (Competência) & 0,0022104 \\
\hline Parceiro (IPPs) X Critério de escolha do parceiro (Confiança) & 0,00000047 \\
\hline Parceiro (fornecedores nacionais) X Critério de escolha do parceiro (Confiança) & 0,02443472 \\
\hline Parceiro (fornecedores nacionais) X Critério de escolha do parceiro (competência) & 0,30475160 \\
\hline
\end{tabular}

Fonte: Autoria própria (2015). 
De acordo com o método, considera-se que há relação entre as variáveis quando o resultado não ultrapassar o valor de “0,005”. Nesse caso, pode-se afirmar que as empresas que utilizam as IPPs como fonte de inovação também utilizam como instrumentos as publicações científicas, o que demonstra relação entre essas duas variáveis. Essa relação não ocorre entre as variáveis concorrentes (como fonte de inovação) e uso de benchmarking, como era esperado.

Em relação às parcerias, verifica-se que as empresas que têm parcerias com IPPs desenvolvem prioritariamente atividades voltadas para o teste de produtos, e raramente para o desenvolvimento de novos produtos, que é feito em parceria com os fornecedores nacionais. As empresas que têm parceria com as IPPs utilizam os critérios competência e confiança na escolha dos parceiros. Por outro lado, não foi encontrada relação entre esses dois critérios de escolha nas parcerias com os fornecedores nacionais.

\section{Conclusões}

A principal contribuição deste artigo foi analisar o processo de $\mathrm{P} \& \mathrm{D}$ na cadeia produtiva de frangos de corte. $\mathrm{O}$ foco da pesquisa foram as empresas que atuam na área de produção (genética, nutrição, equipamentos e sanidade) e na área de industrialização (agroindústrias).

Os resultados obtidos permitem concluir que a maior parte das empresas pesquisadas tem estrutura própria de $P \& D$ e as pesquisas estão mais fortemente direcionadas para o desenvolvimento de produtos ou processos, algumas de forma mais intensiva, buscando inovações tecnológicas, outras apenas para controle de qualidade ou adaptação de produtos.

Essas empresas têm buscado desenvolver as pesquisas em parceria, principalmente as empresas de genética e sanidade. Um fato positivo revelado? Pela pesquisa é que as instituições públicas como universidades e IPPs são parceiras importantes nesse processo. A parceria público-privada tem sido amplamente incentivada pelo governo como forma de compartilhar infraestrutura, recursos humanos e financeiros e os riscos inerentes à atividade de pesquisa. Considerando-se a forte dependência tecnológica do País em relação às tecnologias utilizadas na cadeia, observa-se uma necessidade emergente de unir esforços entre todos os elos da cadeia, tanto público como privado, para diminuir essa dependência.

Nesse contexto, em todas as áreas de P\&D é necessário que o avanço seja contínuo para evitar o sucateamento da base tecnológica, o que poderia levar a um aumento indesejável da dependência de países concorrentes. É preciso estar preparado para atender às exigências de mercado, da legislação sanitária e dos novos padrões de consumo. A cadeia produtiva de frangos de corte brasileira tem uma boa estrutura de P\&D e continuar investindo nessas estruturas, usufruindo do conhecimento e das condições materiais e humanas já acumuladas em diversos centros de pesquisa, é condição primordial para o País se manter mundialmente competitivo nesse setor

Investir em $P \& D$, apesar de ser considerada uma atividade de risco e alto custo, traz benefícios para todos os elos da cadeia. $\mathrm{O}$ aumento da competitividade do setor gera benefícios sociais e econômicos para o País, por meio da comercialização dos produtos.

O benefício do produtor com o uso das tecnologias geradas reflete na redução da mão de obra (automação), maior controle da produção (uso de computadores e sistemas de monitoramento), aumento da qualidade e controle sanitário (biosseguridade). Com isso, o consumidor final passa a ter um produto de maior qualidade, com segurança alimentar e a um custo menor.

Considerando-se a acirrada competição global no mercado de carne de frango, é indispensável que a cadeia continue com uma postura para buscar soluções que atendam às novas e constantes demandas. Essa atitude também permeia a preocupação com a sanidade, que perpassa todos os elos da cadeia.

A liderança do Brasil como o maior exportador de carne de frango é, sem dúvida, resultado dos esforços de P\&D, principalmente nas empresas do elo de produção. Porém, esse aumento na produção traz o desafio de manter essa competitividade. A cooperação entre os elos da cadeia e a manutenção e ampliação de esforços em P\&D foram os fatores que impulsionaram o sucesso da cadeia e possibilitaram enfrentar os desafios e aproveitar as oportunidades.

\section{Referências}

ABPA - Associação Brasileira de Proteína Animal. Relatório anual 2018. Disponível em: < http://abpa-br. 
com.br/storage/files/relatorio-anual-2018.pdf $>$. Acesso em: 15 out. 2018 .

ALVES, J. M. S. Análise de Patentes na Indústria Avícola Internacional. 2003. 133 f. Dissertação (Mestrado) Centro de Estudos e Pesquisas em Agronegócios (Cepan), Universidade Federal do Rio Grande do Sul, 2003.

. et al. Dinâmica inovativa no agronegócio: a inovação tecnológica na avicultura industrial por meio da análise de patentes. Cadernos de Ciência E Tecnologia, Brasília, v. 23, n. 2/3, p. 207-233, maio/dez. 2006.

BASSI, N. S. S., SILVA, C. L. e SANTOYO, A. Inovação, pesquisa e desenvolvimento na agroindústria avícola brasileira. Estudos Sociedade e Agricultura, Rio de Janeiro, v. 2, p. 392-417, 2013.

BEINTEMA, N. M. et al. PED agropecuário no Brasil Politica, Investimentos e Perfil Institucional. Instituto Internacional de Pesquisas Sobre Políticas Alimentares, Fundo Regional de Tecnologia Agropecuária. Empresa Brasileira de Pesquisa Agropecuária. Washington D.C.: ago. 2001.

BUAINAIN, A. C. et al. Agricultura familiar e inovação tecnológica no Brasil: características, desafios e obstáculos. Campinas, SP: Editora da Unicamp, 2007.

COSTA, L. S. et al. Panorama do Setor de Frango de Corte no Brasil e a Participação da Indústria Avícola Paranaense no Complexo Dado seu Alto Grau de Competitividade. In: SIMPÓSIO INTERNACIONAL DE GESTÃO DE PROJETOS, INOVAÇÃO E SUSTENTABILIDADE, São Paulo, 2015.

EMBRAPA SUÍNOS E AVES. Disponível em: < http:// www.cnpsa.embrapa.br>. Acesso em: 20 out. 2013.

ESPÍNDOLA, C. J. Trajetórias do progresso técnico na cadeia produtiva de carne de frango do Brasil. Revista Geosul, Florianópolis, v. 27, n. 53, p. 89-113, jan./jul. 2012.

FERRARESI, A. A. Gestão do Conhecimento, Orientação para o Mercado, Inovatividade e Resultados Organizacionais: Um estudo em empresas instaladas no Brasil. 2010. $213 \mathrm{f}$. Tese (Doutorado em Administração) - Programa de Pós-graduação em Administração, Universidade de São Paulo, São Paulo, 2010.

IPARDES - Instituto Paranaense de Desenvolvimento Econômico e Social. Análise da competitividade da cadeia agroindustrial de carne de frango no Estado do Paraná: sumário executivo / Instituto Paranaense de Desenvolvimento Econômico e Social, Instituto Brasileiro da Qualidade e Produtividade e Grupo de Estudos e Pesquisas Agroindustriais da UFSCAR. Curitiba: IPARDES, 2002. 86 p.

JESUS JUNIOR, C. et al. A cadeia da carne de frango: tensões, desafios e oportunidades. BNDES Setorial, Rio de Janeiro, n. 26, p. 191-232, 2007.

KNORRINGA, P.eMEYER-STAMER, J.New dimensions in local enterprise cooperation and development: from clusters to industrial districts. In UNCTAD (Org.). Cew approaches to science and technology co-operation and capacity building. (ATAS Bulletin XI). New York, Geneve: United Nations, November,1998.

MALHOTRA, N. K. Pesquisa de Marketing. Uma orientação aplicada (Trad. RIBEIRO, L. B.; STEFANI, M. 6. ed.). Porto Alegre: Bookman, 2012.

MARCONI, M. A. e LAKATOS, E. M. Técnicas de pesquisa. 6. ed. São Paulo: Atlas, 2007.

MENDES, A. A., NÄÄS, I. de A. e MACARI, M. Produção de frangos de corte. Campinas: FACTA, 2004, p. 1-22.

MIOR, L. C. Empresas agroalimentares, produção familiar e competitividade no complexo carnes de Santa Catarina. 1992, 400f. Dissertação (Mestrado em Desenvolvimento Agrícola) - Universidade Federal do Rio de Janeiro (UFRRJ/CPDA, Rio de Janeiro/RJ, 1992.

NASCIMENTO, D. E. e LABIAK JUNIOR, S. Ambientes e dinâmicas de cooperação para inovação. Curitiba, Aymará, 2011.

OLIVEIRA, G. B. Uma discussão sobre o conceito de desenvolvimento. Revista da FAE, Curitiba, v. 5, n. 2, p. 41-48, maio/ago. 2002.

OLIVEIRA, L. G. et al. Gerenciamento de riscos na cadeia agroindustrial de frango: análise da perspectiva dos avicultores em ubá, Minas Gerais. Revista Produção Online, v. 15, n. 4, p. 1305-1325, out./dez. 2015.

RECK, A. B. e SCHULTZ, G. Aplicação da metodologia multicritério de apoio à decisão no relacionamento interorganizacional na cadeia da avicultura de corte. Rev. Econ. Sociol. Rural, v. 54, n. 4, p. 709728, dez. 2016. Disponível em: <http://www.scielo. br/scielo.php?script $=$ sci_arttext\&pid $=$ S0103$20032016000400709 \& \operatorname{lng}=\mathrm{pt \& nrm}=\mathrm{iso}>$. Acesso em: 05 jun. 2017.

RIZZI, A. T. Mudanças tecnológicas e reestruturação da indústria agroalimentar: ocaso da indústria de frangos no Brasil. 1993, 203f. Tese (Doutorado em Economia) -Instituto de Economia. Universidade Estadual de Campinas (UNICAMP), Campinas-SP, 1993.

RODRIGUES, F. S. Estratégias de marketing da cadeia agroexportadora brasileira de frango de corte. Seminário de 
Administração FEA-USP, 2007. Disponível em: < http:// www.ead.fea.usp.br/semead/>. Acesso em: 10 out. 2013.

SANTINI, G. A. Dinâmica tecnológica da cadeia e frango de corte no Brasil. Análise dos segmentos de insumo e processamento. 2006, 235f. Tese (Doutorado em Eng. Produção). Universidade Federal de São Carlos (USFCAR), São Carlos, 2006.

. SOUZA FILHO, H. M. Mudanças tecnológicas em cadeias agroindustriais: uma análise dos elos de processamento da pecuária de corte, avicultura de corte e suinocultura. In: CONGRESSO DA SOCIEDADE BRASILEIRA DE ECONOMIA RURAL, 42, 2004, Cuiabá. Anais... Cuiabá, SOBER, 2004, p. 1-12.

SANTORO, M. D. e GOPALAKRISHNAN, S. Relationship dynamics between university research centers and industrial firms: their impact on technology transfer activities. Journal of Technology Transfer, v. 26, p. 163-171, 2001.

SANTOS, G. R. Cadeias Agroindustriais e Avicultura no Brasil: organização produtiva e upgrading por cooperativas. SERIE DOCUMENTOS DEL REPORTE ANUAL 2014, Recursos Naturales y Desarrollo. RED SUDAMERICANA DE ECONOMÍA APLICADA. 2014.

SANTOS, G. E. de O. Cálculo amostral: calculadora on-line. Disponível em: < http://www.calculoamostral. vai.la $>$. Acesso em: 10 mar. 2016.

SHORR, H. Decisão estratégia. In: Anuário da avicultura industrial, n. 1062, dez. 99 - Jan/99, São Paulo-SP.

SEREIA, V. J. A decisão de inovar e os fatores determinantes na escolha de fontes de inovação nas empresas agroindustriais de carne. 2012. $150 \mathrm{f}$. Tese (Doutorado) - Universidade Nove de Julho - UNINOVE, São Paulo, 2012.
SILVA, C. L. e SAES, M. S. M. Estruturas e características da cadeia de valor a partir do tipo de governança: uma avaliação preliminar da avicultura de corte paranaense. Informe Gepec, Toledo, v. 9, n. 1, 2005a.

. e SAES, M. S. M. A Questão da Coexistência de Estruturas de Governança na Economia dos Custos de Transação: evidências empíricas na avicultura de corte Paranaense. Revista de Administração Mackenzie, São Paulo, v. 6, n. 3, 2005b.

SORJ, P. et al. Camponeses e agroindústria. Transformação social e representação política na avicultura brasileira (online). Centro Eldestein de Pesquisa Sociais. Rio de Janeiro: 2008.

SILVEIRA et al. Análise do Sistema Nacional de Inovação no setor de energia na perspectiva das políticas públicas brasileiras. Cad. EBAPE.BR, v. 14, Edição Especial, Artigo 6, Rio de Janeiro, jul. 2016.

SOUZA, I. S. F. A importância do relacionamento pesquisa/extensão para a agropecuária. Cadernos de Ciência e Tecnologia, Brasília, v. 5, n. 1/3, jan./abr. 1988.

TIDD, J., BESSANT, J. e PAVITT, K. Gestão da inovação. 3. ed. Porto Alegre: Bookman, 2008.

VIOLÀ, M. e TRICHES, D. A cadeia de carne de frango: uma análise dos mercados brasileiros e mundial de 2002 a 2010 (Texto no 44), Caxias do Sul, RS, Centro de Ciências Econômicas, Contábeis e Comércio Internacional, Universidade de Caxias do Sul, Instituto de Pesquisas Econômicas e Sociais (IPES) 2013.

YEGANIANTZ, L. e MACEDO, M., M. C. Avaliação de impacto social de pesquisa agropecuária: a busca de uma metodologia baseada em indicadores. Brasilia: Embrapa Informação Tecnológica, 2002. 59p. (Embrapa Informação Tecnológica, 13).

Todo o conteúdo deste periódico, exceto onde estiver identificado, está licenciado sob uma Licença Creative Commons (cc by 4.0). 